\title{
Diagnosis and Management of Autonomic Dysfunction in Dementia Syndromes
}

\section{Louise M. Allan, PhD*}

\author{
Address \\ *Institute of Health Research, College of Medicine and Health, University of \\ Exeter, South Cloisters Building, St Luke's Campus, Heavitree Road, Exeter, EX1 \\ 2LU, UK \\ Email: L.Allan@exeter.ac.uk
}

Published online: 10 July 2019

(C) The Author(s) 2019

This article is part of the Topical Collection on Dementia

Keywords Autonomic nervous system - Dementia - Orthostatic hypotension - Urinary tract symptoms - Lewy body disease

\begin{abstract}
Purpose of review Autonomic dysfunction is common in dementia, particularly in the Lewy body dementias. This review considers the evidence for autonomic dysfunction in dementia, common symptoms and potential management options.

Recent findings Autonomic dysfunction has been shown in Alzheimer's disease and Lewy body dementias. Common symptoms include orthostatic dizziness, syncope, falls, urinary tract symptoms and constipation. Non-pharmacological management of orthostatic hypotension should include bolus water drinking. Pharmacological management may include the use of midodrine or droxidopa although the latter is not available in Europe. Atomoxetine is a noradrenaline reuptake inhibitor which may be useful if further clinical trials become available. Management of constipation may include the use of probiotics, osmotic laxatives such as macrogol and chloride type 2 channel activators such as lubiprostone. Management of urinary tract symptoms may include the use of mirabegron.

Summary There is a dearth of clinical trials for autonomic dysfunction in dementia and most of the evidence is imputed from trials in Parkinson's disease. However, pragmatic recommendations may be made. There is a need for controlled clinical trials in people with dementia.
\end{abstract}




\section{Introduction}

The autonomic or "involuntary" nervous system (ANS) is responsible for the control of many bodily functions that we are not usually aware of, such as heart rate, blood pressure, body temperature, saliva and tear production, pupil size, gut motility and sphincter control. It is one of the most fundamental homeostatic mechanisms within mammalian physiology and can be disturbed in many disease processes. There is a reason to believe that the ANS may be affected by dementia as neuropathological lesions can be found in the ANS in many types of dementia. In Alzheimer's disease (AD), lesions have been found in the insula and anterior cingulate cortex [1]. ANS dysfunction is a common feature of the Lewy body disorders which include Parkinson's disease dementia (PDD) and dementia with Lewy bodies (DLB) [2・]. Aggregates of misfolded alphasynuclein are deposited in the neurons, including axons, forming Lewy bodies and Lewy neurites. These are found in the post-synaptic peripheral autonomic neurons. DLB is also associated with underactivity of the cholinergic nervous system [3]. Acetylcholine is essential for parasympathetic and pre-ganglionic sympathetic neurotransmission.

Common symptoms of ANS dysfunction are outlined in Table 1 and include orthostatic dizziness, syncope, falls, urinary tract symptoms and constipation. Orthostatic symptoms are typically worse in the morning, after meals, during a rise in body temperature, with prolonged standing, and with physical activity. Total autonomic symptom scores, urinary symptoms, constipation and postural dizziness have been shown to be significantly higher in PDD, DLB and vascular dementia (VAD) patients than either controls or $\mathrm{AD}$ patients and are associated with reduced activities of daily living, depression and poorer quality of life [4]. Falls are a particularly significant symptom as they are associated with the subsequent decline in activities of daily living, institutionalisation and mortality. Orthostatic hypotension has been shown to be a risk factor for falls in dementia [5]. Orthostatic hypotension may be associated with poorer cognitive prognosis in Parkinson's disease (PD), but whether this is due to causation or association with more severe underlying disease is unclear $[6,7]$.

A number of studies have examined ANS dysfunction in dementia. The results in $\mathrm{AD}$ have been conflicting, with some studies showing evidence of ANS dysfunction [8-12] and some studies showing that some patients may have evidence of autonomic neuropathy but as a group, no deficits in heart rate variability [13•, 14]. A recent meta-analysis of heart rate variability studies in AD also showed conflicting evidence with deficits in the time domain rather than the frequency domain and high heterogeneity of results [15]. VAD may also be associated with some ANS dysfunction, but again the evidence is conflicting [13•, 14, 16, 17]. However, as

Table 1. Symptoms of autonomic dysfunction

\section{Symptoms of orthostatic hypotension}

Light-headedness or dizziness

Syncope

Falls

Weakness

Fatigue

Head and neck pain (coat hanger pain)

Vertigo

Pallor

Clamminess

Blurred vision

Palpitations

Tremulousness

Cognitive difficulties

Anxiety

\section{Other autonomic symptoms}

Bloating, nausea and vomiting

Dysphagia

Dry mouth or sialorrhoea

Dry eyes

Loss of sweating or excessive sweating

Sensitivity to glare

Diarrhoea and constipation

Urinary frequency, urgency and urge incontinence

Urinary retention

Erectile dysfunction 
expected, the most prominent ANS dysfunction has been shown in the Lewy body dementias [13•, 18-21]. The study of orthostatic hypotension $(\mathrm{OH})$ alone may indicate some ANS dysfunctions, and $\mathrm{OH}$ has been shown to be more common in all types of dementia, but other factors may also contribute to $\mathrm{OH}$ in dementia [13•, 22-24]. Orthostatic hypotension may be asymptomatic in dementia [25].

\section{Diagnosis}

Clinical autonomic function testing usually focuses upon the neurocardiovascular system as this can be investigated non-invasively. Commonly used tests include the measurement of orthostatic changes in blood pressure and heart rate, the cardiovascular responses to the Valsalva manoeuvre (expiration against a closed glottis), respiratory sinus arrhythmia during respiration at a controlled frequency, response to a cold stimulus (cold pressor test) and isometric exercise [26]. Abnormalities in more than 3 of these tests are usually taken as an indication of clinically significant autonomic failure [27]. Alternatively, a composite scoring system may be used which has been shown to correlate with severity of disease and prognosis in other common causes of autonomic neuropathy [28]. In the clinic, a simple measurement of orthostatic blood pressure change is the most commonly used test. Orthostatic hypotension is defined in recent consensus criteria as a sustained reduction of systolic blood pressure of at least $20 \mathrm{mmHg}$ or diastolic blood pressure of $10 \mathrm{mmHg}$ within 3 min of standing or head-up tilt to at least $60^{\circ}$ on a tilt table. In patients with supine hypertension, a reduction in systolic blood pressure of $30 \mathrm{mmHg}$ may be a more appropriate criterion for orthostatic hypotension because the magnitude of the orthostatic blood pressure fall is dependent on the baseline blood pressure [29]. An active stand is probably preferable to a tilt test as it reproduces normal activity. It is not clear whether intermittent blood pressure measurement or beat-to-beat measurement is most appropriate for the diagnosis of orthostatic hypotension. The beat-to-beat measurement may detect some transient drops in blood pressure which are of unknown prognostic significance [30]. Baroreflex failure may result in supine hypertension in some patients.

Heart rate variability has been used to detect ANS dysfunction, but this is a research tool and is not useful for the clinical diagnosis of ANS dysfunction. Meta-iodobenzylguanidine (MIBG) is a physiological analogue of norepinephrine, and cardiac ${ }^{123}$ I-MIBG scintigraphy has previously been used as a noninvasive method of screening for local myocardial sympathetic nerve damage in various cardiac and neurological diseases. The fourth consensus report of the diagnostic criteria for DLB recommends that MIBG scanning may be used as a biomarker of DLB [31].

The assessment of dysphagia may be undertaken by oropharyngeal videofluoroscopy and constipation by measurement of stool transit time. Urinary symptoms may be investigated by urodynamic testing which may show neurogenic detrusor overactivity. Other methods of evaluation of autonomic function include quantitative sudomotor axon testing, thermoregulatory sweat testing, sympathetic skin response, microneurography, pupillography, 
measurement of tear production, nocturnal penile tumescence studies and sphincter electromyography, but these are usually undertaken in specialist centres.

\section{Current treatment}

There are few clinical trials which have examined the management of ANS dysfunction specifically in dementia. Therefore, current management has to be pragmatic and is guided by the evidence for the management of ANS dysfunction in related populations. There is some evidence for the management of $\mathrm{OH}$ in older people in general and there is also a body of evidence for the management of ANS dysfunction in Parkinson's disease which is of particular relevance to the Lewy body dementias.

Orthostatic hypotension

\section{Non-pharmacological interventions}

Initial management of $\mathrm{OH}$ is non-pharmacological. Other causes of $\mathrm{OH}$ besides ANS dysfunction, such as dehydration and medications, should be sought and treated. Hypotensive drugs have been reported to be associated with syncope in dementia [32]. These include diuretics, nitrates, $\alpha$-blockers and angiotensinconverting enzyme inhibitors. However, the effect of stopping antihypertensives on $\mathrm{OH}$ is not necessarily clear. Studies have shown an association between antihypertensives and $\mathrm{OH}$ but these have been observational [33]. There is some evidence from a randomised controlled trial of withdrawal of antihypertensives that prevalence of $\mathrm{OH}$ was reduced in those who did withdraw the drugs, but intention to treat analyses were not significant [34]. Conversely, the SPRINT trial found a lower prevalence of $\mathrm{OH}$ in intensively treated patients, but this did not apply to older groups and people with a standing BP of less than $115 \mathrm{mmHg}$ were excluded from the study [35].

Patients should be given conservative advice about avoiding sudden changes in posture, maintaining their fluid and salt intake to ensure adequate hydration, eating smaller and more frequent meals and avoiding heat stressors such as hot tubs. However, patients should avoid physical inactivity which worsens ANS function due to physical deconditioning. Some experts recommend measuring urinary sodium excretion to determine whether salt intake is adequate and if not to replace salt with either increased dietary intake or salt tablets. Patients who have a 24-h urinary sodium excretion of below $170 \mathrm{mmol}$ can be treated with 1-2-g supplemental sodium three times a day [36]. Elevating the head of the bed has been recommended to reduce nocturia and supine hypertension [36], but a systematic review did not find any evidence that this is effective [37]. Specific non-pharmacological interventions include bolus water drinking, physical counter-manoeuvres (standing cross-legged), lower limb compression and abdominal compression [38]. A recent qualitative study has shown that physical counter-manoeuvres were the most popular non-pharmacological therapy in older people as they are convenient, require no equipment and can be done as required. However, people with dementia may have difficulty learning these manoeuvres. Bolus water drinking ( $480 \mathrm{ml}$ of room-temperature tap water, to 
consume as much as possible within $5 \mathrm{~min}$ ) is also well tolerated and acceptable to patients, but some do have concerns about urinary frequency. Lower limb and abdominal compression were the least acceptable. Stockings may be difficult to get on and aesthetically unpleasing and abdominal binders may be uncomfortable [39]. In terms of efficacy, bolus water drinking has been found to be the most efficacious intervention, followed by abdominal compression and physical counter-manoeuvres. Compression stockings were the least efficacious [40].

\section{Pharmacological interventions}

If non-pharmacological measures are insufficient, then pharmacological interventions may be required. Midodrine is a prodrug whose metabolite, desglymidodrine, is an agonist of $\alpha_{1}$ adrenoceptors that increase vascular resistance and blood pressure. It may be used in Europe and the USA. It is the only licensed pharmacological treatment for $\mathrm{OH}$ in the UK. A systematic review of 7 trials including 325 patients has shown that midodrine increases the standing BP but does not improve postural drop. However, there is some evidence that symptoms are improved. Evidence is of low quality and further trials are required [41]. Treatment is started at $2.5 \mathrm{mg}$ once or twice daily and may be increased up to $10 \mathrm{mg}$ three times daily. The first dose should be taken $1 \mathrm{~h}$ before rising and the last dose at least $4 \mathrm{~h}$ before bedtime to avoid supine hypertension. Side effects of midodrine include hypertension, scalp tingling and piloerection. Contraindications are liver disease, severe heart disease, acute kidney injury, urinary retention, phaeochromocytoma and thyrotoxicosis.

Droxidopa is a more recent drug for neurogenic $\mathrm{OH}$ which has mainly been used in Japan but has now received FDA approval in the USA. It is not licensed in Europe. Droxidopa is a norepinephrine prodrug that is converted into norepinephrine both in the central nervous system and in peripheral tissues, including sympathetic peripheral nerve endings. A meta-analysis of four trials including 494 patients showed that it was effective in reducing dizziness, overall symptoms and difficulty with activity. Droxidopa was also effective in improving standing systolic blood pressure [42•]. Treatment may commence at $100 \mathrm{mg}$ three times daily increasing to $600 \mathrm{mg}$ three times daily. Like midodrine, it should be given during waking hours and avoided before bedtime to avoid supine hypertension. Side effects include headache, dizziness, nausea, fatigue and supine hypertension. Caution is advised in patients with congestive heart failure and chronic renal failure.

Atomoxetine is a noradrenaline reuptake inhibitor which exerts a vasopressor effect and is an emerging therapy for $\mathrm{OH}$. In a randomised controlled trial, atomoxetine produced a greater pressor response in upright systolic blood pressure compared with midodrine [43]. Further clinical trials of this agent are required. The most common side effects are decreased appetite, dry mouth, insomnia and nausea. Severe hepatitis has been anecdotally reported.

Fludrocortisone is often used off-label to treat $\mathrm{OH}$ but evidence for its use is

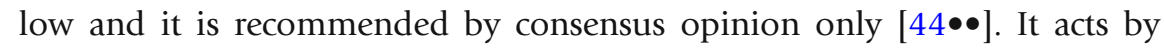
increasing renal sodium and water reabsorption, thus expanding intravascular blood volume. There may be long-term effects of increased vascular resistance. Treatment begins at $100 \mu \mathrm{g}$ once daily increasing to $200 \mu \mathrm{g}$ once daily. Side 
effects include supine hypertension, hypokalemia and oedema. Caution is advised in patients with congestive heart failure.

Cholinesterase inhibitors such as pyridostigmine have been suggested as treatments for $\mathrm{OH}$. Most patients with neurodegenerative dementias will already be on cholinesterase inhibitors. Lower rates of $\mathrm{OH}$ have been reported in a Cochrane review of rivastigmine treatment for PDD [45] and improved responses to orthostasis in $\mathrm{AD}$ have been shown [46]. However, another study has shown worsened heart rate variability in people with dementia treated with donepezil [47].

\section{Supine hypertension}

Supine hypertension in neurogenic $\mathrm{OH}$ patients is arbitrarily defined as a systolic blood pressure above $150 \mathrm{mmHg}$ or diastolic pressure above

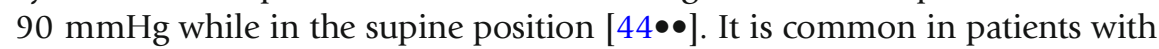
chronic ANS dysfunction and difficult to manage because its treatment has to be balanced with treatment for $\mathrm{OH}$, with management of one condition often exacerbating the other. Expert recommendations for the management of supine hypertension in the setting of neurogenic $\mathrm{OH}$ suggest that supine hypertension requires intervention if systolic blood pressure exceeds the range of 160$180 \mathrm{mmHg}$, but in patients with the largest drops in orthostatic BP, this may have to be tolerated to avoid symptoms of $\mathrm{OH}$ and the increased risk of falls [44••]. Patients with neurogenic $\mathrm{OH}$ and supine hypertension should be advised to avoid supine posture during the day and elevate the head of the bed as tolerated during the night. Fludrocortisone should be avoided and shortacting antihypertensives such as captopril $25 \mathrm{mg}$, hydralazine $10-25 \mathrm{mg}$ or nitroglycerine patch $(0.1 \mathrm{mg} / \mathrm{h}$, remove in the morning) may be given at night. Patients should be warned about the risk of falls when getting up at night because of $\mathrm{OH}$; a bedside urinal or commode may be required.

Patients with dysphagia should be referred to a speech and language therapist. Useful interventions may include postural and behavioural changes such as reduced meal volumes and slow eating. Expiratory muscle strength training (EMST) and video-assisted swallowing therapy (VAST) may be effective dysphagia treatments in PD [48]. A randomised control trial exploring interventions to prevent aspiration including 132 PDD with dysphagia found lower rates of aspiration as evidenced on videofluoroscopy, with honey-thickened fluids [49]. Another study noted improved swallowing function objectively in 48 Lewy body dementia patients referred for videofluoroscopy with carbonated liquids [50]. In patients with severe dementia, it may be appropriate to consider at risk feeding, in which the risk of aspiration is tolerated in order to improve quality of life [51].

Sialorrhoea is often due to reduced swallowing frequency and a portable metronomic brooch to act as a reminder to swallow may help. Local anticholinergics are not suitable for patients with dementia because of their cognitive side effects. A randomised cross-over trial of glycopyrrolate $(1 \mathrm{mg}$, twice or three times a day) in 23 PD patients found that 9 of patients had a clinically relevant improvement in sialorrhoea 75 over a 4 -week period [52]. Side effects include dry mouth, urinary retention, constipation and blurred vision. An 
evidence-based review of botulinum toxin injection to the salivary glands appears effective and safe in $\mathrm{PD}$, although repeat injections are typically required every 3 to 6 months [53].

\section{Gastroparesis}

Dietary modifications, including a low-fat diet with small frequent meals and liquid nutrients, can help with gastroparesis $[2 \bullet] . \mathrm{D}_{2}$ receptor blockers such as metoclopramide and domperidone have been used but are associated with an increase in the QT interval and risk of arrhythmia. Erythromycin and azithromycin stimulate motilin receptors but adverse events include gastrointestinal toxicity, ototoxicity, antibiotic resistance and QT prolongation. Muscarinic agonists and cholinesterase inhibitors may be used but many patients may already be on cholinesterase inhibitors. Ghrelin receptor agonists are being tested in clinical trials [54].

Non-pharmacological interventions may help with the initial management of constipation. These include increasing the amount of fibre in the diet, increasing fluid intake and increasing physical activity. Medications which may exacerbate constipation such as anticholinergic agents and opiates should be reviewed. One controlled clinical trial found that fermented milk products with probiotics (e.g. kefir) resulted in a higher increase in the number of complete bowel movements in patients with PD [55].

Pharmacological interventions include the use of bulk laxatives such as psyllium and osmotic laxatives such as polyethylene glycol (macrogol). Psyllium has been shown to increase the frequency of bowel movement in PD patients [56]. A randomised controlled trial of macrogol showed an improvement in symptoms of constipation in PD patients [57]. Lubiprostone is a locally acting chloride type 2 channel activator. In a randomised controlled clinical trial of PD patients, a marked or very marked clinical global improvement was reported by 16 of 25 (64.0\%) subjects receiving drug vs 5 of 27 (18.5\%) subjects receiving placebo [58].

Urinary symptoms in ANS dysfunction may be related to detrusor overactivity or underactivity. Non-pharmacological interventions include increasing fluid intake because concentrated urine may exacerbate detrusor overactivity. Bladder training may help and has been found to be useful in a recent pilot trial in PD, but has not been investigated in dementia and may be more difficult for dementia patients to undertake.

Anti-muscarinic drugs which are usually used to treat detrusor overactivity are better avoided in dementia because of their cognitive side effects. Mirabegron is a selective $\beta 3$-adrenergic receptor which elicits relaxation of the detrusor muscle during the storage phase and improves bladder capacity. It has been suggested as an option for the management of urinary symptoms in dementia by the National Institute of Health and Clinical Excellence [59]. Treatment can be commenced at 25-50 mg once daily. Side effects include urinary retention, pelvic/abdominal pain and hypertension. 
Incomplete bladder emptying is uncommon in dementia but can occur if ANS dysfunction is present. If the post-void residual is greater than $100 \mathrm{ml}$, then intermittent self-catheterisation can be considered. This may need to be performed by a caregiver. If this is not possible, then an indwelling catheter may have to be considered.

\section{Sexual dysfunction}

Erectile dysfunction, problems with ejaculation and difficulty achieving orgasm are common in ANS dysfunction. Contributing factors such as stress, depression, anxiety and medications should be considered. Diuretics, $\beta$-blockers and selective serotonin reuptake inhibitors can all cause erectile dysfunction. Options for management of erectile dysfunction include phosphodiesterase type 5 (PDE-5) inhibitors, intracavernosal injection therapy, vacuum pump devices, intraurethral prostaglandin suppositories and surgical placement of penile prostheses. When prescribing PDE 5 inhibitors, a short-acting agent such as sildenafil should be used because of the risk of hypotension.

\section{Sweating}

Excessive sweating is common in PD patients. There are no treatment trials but there was a consensus from a recent expert Delphi panel group that patients may benefit from the use of loose-fitting clothing, cotton bedding for night sweats and antiperspirants as well as avoidance of triggers, e.g. alcohol, spicy foods and hot rooms [60].

\section{Compliance with Ethical Standards}

Conflict of Interest

Professor Allan reports grant funding from the National Institute of Health Research, the Alzheimer's Society, Alzheimer's Research UK and Parkinson's UK. She has received speaker fees from Healthcare UK Conferences Ltd. outside the submitted work.

Human and Animal Rights and Informed Consent

This article does not contain any studies with human or animal subjects performed by any of the authors.

\section{Open Access}

This article is distributed under the terms of the Creative Commons Attribution 4.0 International License (http://creativecommons.org/licenses/by/4.0/), which permits unrestricted use, distribution, and reproduction in any medium, provided you give appropriate credit to the original author(s) and the source, provide a link to the Creative Commons license, and indicate if changes were made. 
Papers of particular interest, published recently, have been highlighted as:

- Of importance

$\bullet \quad$ Of major importance

1. Chu CC, Tranel D, Damasio AR, Van Hoesen GW. The autonomic-related cortex: pathology in Alzheimer's disease. Cereb Cortex. 1997;7(1):86-95.

2. Palma JA, Kaufmann H. Treatment of autonomic dysfunction in Parkinson disease and other synucleinopathies. Mov Disord. 2018;33(3):372-9.

A very useful and comprehensive description of autonomic dysfunction in PD.

3. Perry EK, Marshall E, Perry RH, Irving D, Smith CJ, Blessed $\mathrm{G}$, et al. Cholinergic and dopaminergic activities in senile dementia of Lewy body type. Alzheimer Dis Assoc Disord. 1990;4(2):87-95.

4. Allan L, McKeith I, Ballard C, Kenny RA. The prevalence of autonomic symptoms in dementia and their association with physical activity, activities of daily living and quality of life. Dement Geriatr Cogn Disord. 2006;22(3):230-7.

5. Allan LM, Ballard CG, Rowan EN, Kenny RA. Incidence and prediction of falls in dementia: a prospective study in older people. PLoS ONE[Electronic Resource]. 2009;4(5):e5521.

6. McDonald C, Newton JL, Burn DJ. Orthostatichypotension and cognitive impairment in Parkinson's disease: causation or association? Mov Disord. 2016;31(7):937-46.

7. Fanciulli A, Strano S, Colosimo C, Caltagirone C, Spalletta G, Pontieri FE. The potential prognostic role of cardiovascular autonomic failure in alphasynucleinopathies. Eur J Neurol. 2013;20(2):231-5.

8. Elmstahl S, Petersson M, Lilja B, Samuelsson SM, Rosen I, Bjuno L. Autonomic cardiovascular responses to tilting in patients with Alzheimer's disease and in healthy elderly women. Age Ageing. 1992;21(4):301-7.

9. Vitiello B, Veith RC, Molchan SE, Martinez RA, Lawlor BA, Radcliffe J, et al. Autonomic dysfunction in patients with dementia of the Alzheimer type. Biol Psychiatry. 1993;34(7):428-33.

10. Wang SJ, Liao KK, Fuh JL, Yamada M. Cardiovascular autonomic functions in Alzheimer's disease. Age Ageing. 1994;23(5):400-4.

11. Algotsson A, Viitanen M, Winblad B, Solders G. Autonomic dysfunction in Alzheimer's disease. Acta Neurol Scand. 1995;91(1):14-8.

12. Idiaquez J, Sandoval E, Seguel A. Association between neuropsychiatric and autonomic dysfunction in Alzheimer's disease. Clin Auton Res. 2002;12(1):43-6.

13. Allan L, Ballard C, Allen J, Murray A, Davidson A, McKeith I, et al. Autonomic dysfunction in dementia. J Neurol Neurosurg Psychiatry. 2007;78(7):671-.

The most comprehensive evaluation of autonmic dysfunction in dementia.

14. Allan LM, Kerr SR, Ballard CG, Allen J, Murray A, McLaren AT, et al. Autonomic function assessed by heart rate variability is normal in Alzheimer's disease and vascular dementia. Dement Geriatr Cogn Disord. 2005;19(2-3):140-4.

15. Da Silva VP, Oliveira BRR, Mello RGT, Moraes $\mathrm{H}_{\text {, }}$ Deslandes AC, Laks J. Heart rate variability indexes in dementia: a systematic review with a quantitative analysis. Curr Alzheimer Res. 2018;15(1):80-8.

16. Yamamoto T, Shimazu K, Tamura N, Watanabe S, Hamaguchi K. [Autonomic nervous functions in Alzheimer type and multi-infarct dementia-a hemodynamic study]. [Japanese]. Rinsho Shinkeigaku Clin Neurol. 1990;30(9):1020-2.

17. Niimi $Y$, Watanabe $M$, Nishimura R, Mano K, Watanabe H. [Baroreflex function in patients with Binswanger's encephalopathy]. [Japanese]. Rinsho Shinkeigaku Clin Neurol. 1999;39(7):700-4.

18. Kasanuki K, Iseki E, Fujishiro H, Ando S, Sugiyama H, Kitazawa M, et al. Impaired heart rate variability in patients with dementia with Lewy bodies: efficacy of electrocardiogram as a supporting diagnostic marker. Parkinsonism Relat Disord. 2015;21(7):749-54.

19. Watanabe H, Ieda T, Katayama T, Takeda A, Aiba I, Doyu M, et al. Cardiac (123)I-meta-

iodobenzylguanidine (MIBG) uptake in dementia with Lewy bodies: comparison with Alzheimer's disease. J Neurol Neurosurg Psychiatry. 2001;70(6):781-3.

20. Yoshita M, Taki J, Yamada M. A clinical role for [(123)I]MIBG myocardial scintigraphy in the distinction between dementia of the Alzheimer's-type and dementia with Lewy bodies.[comment]. J Neurol Neurosurg Psychiatry. 2001;71(5):583-8.

21. Kashihara K, Ohno M, Kawada S, Okumura Y. Reduced cardiac uptake and enhanced washout of 123I-MIBG in pure autonomic failure occurs conjointly with Parkinson's disease and dementia with Lewy bodies. J Nucl Med. 2006;47(7):1099-101.

22. Passant U, Warkentin S, Gustafson L. Orthostatic hypotension and low blood pressure in organic dementia: a study of prevalence and related clinical characteristics. Int J Geriatr Psychiatry. 1997;12(3):395-403.

23. Mehrabian S, Duron E, Labouree F, Rollot F, Bune A, Traykov L, et al. Relationship between orthostatic hypotension and cognitive impairment in the elderly. J Neurol Sci. 2010;299(1-2):45-8.

24. Sonnesyn H, Nilsen DW, Rongve A, Nore S, Ballard C, Tysnes OB, et al. High prevalence of orthostatic hypotension in mild dementia. Dement Geriatr Cogn Disord. 2009;28(4):307-13.

25. Bengtsson-Lindberg $M$, Larsson $V$, Minthon L, Wattmo C, Londos E. Lack of orthostatic symptoms in dementia patients with orthostatic hypotension. Clin Auton Res. 2015;25(2):87-94. 
26. Anonymous. Assessment: clinical autonomic testing report of the Therapeutics and Technology Assessment Subcommittee of the American Academy of Neurology. Neurology. 1996;46(3):873-80.

27. Ewing DJ, Martyn CN, Young RJ, Clarke BF. The value of cardiovascular autonomic function tests: 10 years experience in diabetes. Diabetes Care. 1985;8(5):491-8.

28. Low PA. Composite autonomic scoring scale for laboratory quantification of generalized autonomic failure. Mayo Clin Proc. 1993;68(8):748-52.

29. Freeman R, Wieling W, Axelrod FB, Benditt DG, Benarroch E, Biaggioni I, et al. Consensus statement on the definition of orthostatic hypotension, neurally mediated syncope and the postural tachycardia syndrome. Clin Auton Res. 2011;21(2):69-72.

30. Frith J. Diagnosing orthostatic hypotension: a narrative review of the evidence. Br Med Bull. 2015;115(1):123-34.

31. McKeith IG, Boeve BF, Dickson DW, Halliday G, Taylor JP, Weintraub D, et al. Diagnosis and management of dementia with Lewy bodies: fourth consensus report of the DLB consortium. Neurology. 2017;89(1):88-100.

32. Testa G, Ceccofiglio A, Mussi C, Bellelli G, Nicosia F, Bo $\mathrm{M}$, et al. Hypotensive drugs and syncope due to orthostatic hypotension in older adults with dementia (Syncope and Dementia Study). J Am Geriatr Soc. 2018;66(8):1532-7.

33. Frith J, Parry SW. New horizons in orthostatic hypotension. Age Ageing. 2017;46(2):168-74.

34. Moonen JE, Foster-Dingley JC, de Ruijter W, van der Grond J, de Craen AJ, van der Mast RC. Effect of discontinuation of antihypertensive medication on orthostatic hypotension in older persons with mild cognitive impairment: the DANTE Study Leiden. Age Ageing. 2016;45(2):249-55.

35. Group SR. Wright JT, Jr., Williamson JD, Whelton PK, Snyder JK, Sink KM, et al. A randomized trial of intensive versus standard blood-pressure control. N Engl J Med. 2015;373(22):2103-16.

36. Low PA, Singer W. Management of neurogenic orthostatic hypotension: an update. Lancet Neurol. 2008;7(5):451-8.

37. Logan IC, Witham MD. Efficacy of treatments for orthostatic hypotension: a systematic review. Age Ageing. 2012;41(5):587-94.

38. Mills PB, Fung CK, Travlos A, Krassioukov A. Nonpharmacologic management of orthostatic hypotension: a systematic review. Arch Phys Med Rehabil. 2015;96(2):366-75 e6.

39. Robinson LJ, Pearce RM, Frith J. Acceptability of nondrug therapies in older people with orthostatic hypotension: a qualitative study. BMC Geriatr. 2018;18(1):315.

40. Newton JL, Frith J. The efficacy of nonpharmacologic intervention for orthostatic hypotension associated with aging. Neurology. 2018;91(7):e652-e6.

41. Parsaik AK, Singh B, Altayar O, Mascarenhas SS, Singh SK, Erwin PJ, et al. Midodrine for orthostatic hypotension: a systematic review and meta-analysis of clinical trials. J Gen Intern Med. 2013;28(11):1496-503.
42.• Strassheim V, Newton JL, Tan MP, Frith J. Droxidopa for orthostatic hypotension: a systematic review and meta-analysis. J Hypertens. 2016;34(10):1933-4.

The most recent review of the evidence for droxidopa.

43. Ramirez CE, Okamoto LE, Arnold AC, Gamboa A, Diedrich A, Choi L, et al. Efficacy of atomoxetine versus midodrine for the treatment of orthostatic hypotension in autonomic failure. Hypertension. 2014;64(6):1235-40.

44.• Gibbons CH, Schmidt P, Biaggioni I, Frazier-Mills C, Freeman $\mathrm{R}$, Isaacson $\mathrm{S}$, et al. The recommendations of a consensus panel for the screening, diagnosis, and treatment of neurogenic orthostatic hypotension and associated supine hypertension. J Neurol. 2017;264(8):1567-8.

A key paper for the diagnosis of orthostatic hypotension.

45. Maidment I, Fox C, Boustani M. Cholinesterase inhibitors for Parkinson's disease dementia. Cochrane Database Syst Rev. 2006;(1):CD004747.

46. da Costa Dias FL, da Silva RMFL, de Moraes EN, Caramelli P. Cholinesterase inhibitors modulate autonomic function in patients with Alzheimer's disease and mixed dementia. Curr Alzheimer Res.

2013;10(5):476-81.

47. McLaren AT, Allen J, Murray A, Ballard CG, Kenny RA. Cardiovascular effects of donepezil in patients with dementia. Dement Geriatr Cogn Disord. 2003;15(4):183-8.

48. van Hooren MR, Baijens LW, Voskuilen S, Oosterloo M, Kremer B. Treatment effects for dysphagia in Parkinson's disease: a systematic review. Parkinsonism Relat Disord. 2014;20(8):800-7.

49. Logemann JA, Gensler G, Robbins J, Lindblad AS, Brandt D, Hind JA, et al. A randomized study of three interventions for aspiration of thin liquids in patients with dementia or Parkinson's disease. J Speech Lang Hear Res. 2008;51(1):173-83.

50. Larsson V, Torisson G, Bulow M, Londos E. Effects of carbonated liquid on swallowing dysfunction in dementia with Lewy bodies and Parkinson's disease dementia. Clin Interv Aging. 2017;12:1215-22.

51. Murray A, Mulkerrin S, O'Keeffe ST. The perils of 'risk feeding'. Age Ageing. 2019;02:02.

52. Arbouw ME, Movig KL, Koopmann M, Poels PJ, Guchelaar HJ, Egberts TC, et al. Glycopyrrolate for sialorrhea in Parkinson disease: a randomized, doubleblind, crossover trial. Neurology. 2010;74(15):1203-7.

53. Fasano A, Visanji NP, Liu LW, Lang AE, Pfeiffer RF. Gastrointestinal dysfunction in Parkinson's disease. Lancet Neurol. 2015;14(6):625-39.

54. Sanger GJ, Furness JB. Ghrelin and motilin receptors as drug targets for gastrointestinal disorders. Nat Rev Gastroenterol Hepatol. 2016;13(1):38-48.

55. Barichella M, Pacchetti C, Bolliri C, Cassani E, Iorio L, Pusani C, et al. Probiotics and prebiotic fiber for constipation associated with Parkinson disease: an RCT. Neurology. 2016;87(12):1274-80.

56. Ashraf W, Pfeiffer RF, Park F, Lof J, Quigley EM. Constipation in Parkinson's disease: objective assessment 
and response to psyllium. Mov Disord.

1997;12(6):946-51.

57. Zangaglia R, Martignoni E, Glorioso M, Ossola M, Riboldazzi G, Calandrella D, et al. Macrogol for the treatment of constipation in Parkinson's disease. a randomized placebo-controlled study. Mov Disord. 2007;22(9):1239-44.

58. Ondo WG, Kenney C, Sullivan K, Davidson A, Hunter C, Jahan I, et al. Placebo-controlled trial of lubiprostone for constipation associated with Parkinson disease. Neurology. 2012;78(21):1650-4.

59. NICE. Dementia: assessment, management and support for people living with dementia and their carers.
London: National Institute for Health and Care Excellence; 2018.

60. Taylor J, McKeith I, Burn D, Boeve B, Weintraub D, Bamford C, et al. Management of Lewy body dementia. Lancet Neurol. 2019; In press.

\section{Publisher's Note}

Springer Nature remains neutral with regard to jurisdictional claims in published maps and institutional affiliations. 